\title{
ARQUITECTURA Y SECUENCIA OCUPACIONAL EN LAS VILLAE DE LAS VEGAS BAJAS DEL GUADIANA. EL CASO DE TORRE ÁGUILA (MONTIJO, BADAJOZ)
}

\author{
Rosalía María Durán Cabello, Francisco Germán Rodríguez Martín y Ángel Morillo Cerdán
}

\begin{abstract}
Resumen
En esta comunicación se aborda el análisis de la arquitectura y de la técnica constructiva de la uilla de Torre Águila, incidiendo en aspectos tales como la elección de los opera empleados; la relación existente entre el tipo constructivo y la cronología; las reparaciones realizadas así como los materiales constructivos utilizados en las mismas. En el estudio también se contemplará la cuestión espacial interna de la uilla: las ampliaciones y reestructuraciones de los distintos espacios no sólo en razón de su funcionalidad, asimismo se tratará el proceso de su paulatino abandono. Los datos aportados serán cotejados con otros establecimientos rurales de su entorno inmediato.
\end{abstract}

\section{INTRODUCCIÓN}

En esta comunicación queremos presentar un primer acercamiento a la arquitectura de la villa, realizando una descripción de las diferentes técnicas constructivas utilizadas. Se subrayan las peculiaridades de cada aparejo, al tiempo que se ponen de relieve otros aspectos constructivos como: razones tectónicas del empleo de uno u otro aparejo; la homogeneidad de las fábricas; el sistema constructivo de cada fase de existencia de la villa, esto es una aproximación crono-arquitectónica; también se hacen algunas reflexiones de tipo mensiocronológico ${ }^{1}$, etc.

${ }^{1}$ Dado el nivel de arrasamiento de la villa del s.II, en muchos casos a nivel de cimientos, no podemos elevar a nivel de conclusiones definitivas o, hipótesis, los resultados del análisis estadístico de las medidas de los diferentes elementos constructivos. Sí podemos hablar de las técnicas de construcción y de su regularidad, empleada no sólo en esta villa sino en todos los asentamientos rurales de la vega del Guadiana.
La arquitectura privada, en este caso de una villa, no es parangonable, excepto en rarísimas ocasiones ${ }^{2}$, con la arquitectura pública ${ }^{3}$. Esto se hace patente en sus volúmenes, en la regularidad de sus fábricas, y en su finalidad. Hay que hacer notar, también, que, en las construcciones domésticas rurales, se recurre siempre a la materia prima constructiva -0 susceptible de ser transformada para tal fin- que se encuentra en su entorno más inmediato. Este hecho, ampliamente documentado en la arquitectura pública, tiene su máxima expresión en la arquitectura rural. Tampoco debemos olvidar que el sistema productivo

\footnotetext{
${ }^{2}$ Mencionaremos tan sólo tres ejemplos Villa Adriana, en Tívoli (Salza Prina Ricoti, 2001); Piazza Armerina, en Sicilia (Carandini et alii, 1982) o Cercadilla, en Córdoba (Hidalgo Prieto, 1996).

${ }^{3}$ Estos se ha puesto de manifiesto en múltiples trabajos referidos a la arquitectura urbana privada, como los dedicados a Itálica por Roldán Gómez (1988 y 1991) o a Mérida por Durán Cabello (1991) , Robador González (2000)
} 
y la organización del trabajo, son completamente diferentes de lo que supone acometer una gran empresa pública.

localización.- La villa de Torre Águila se encuentra en el término municipal de Barbaño (Montijo, Badajoz). Se encuentra en las inmediaciones de la antigua vía XII del Iter ab Emeritam Olisipone y el río Ana. Dista 16 millia passum de la capital de Lusitania, Augusta Emerita.

El lugar elegido se encuentra sobre una pequeña elevación de terreno aluvial, que permitía mantener a la villa, y a sus ocupantes, a salvo de las crecidas del Guadiana. Pero este planteamiento de los primeros inquilinos, es erróneo, ya que no contaron con la variabilidad del cauce del río. Tanto es así, que parte de la villa del s IV, ha sido arrastrada por el Ana (Fig. $1)$.

\section{CARACTERÍSTICAS GENERALES DE LAS TÉCNICAS CONSTRUCTIVAS.}

En la villa de Torre Águila se documentan varias técnicas constructivas: opus caementicium, opus incertum, opus testaceum, opus quadratum, tapial y opus signinum. Esta enumeración poco tiene que ver con el volumen construido de cada manera. La técnica representada en menor medida es el opus quadratum, mientras que lo más empleado es el opus incertum con núcleo de opus caementicium, aunque como se verá más adelante, se distinguen dos grandes formas de ejecutarlo. Respecto al opus testaceum, su presencia es notable aunque su aparición se reduce a desempeñar ciertos cometidos técnicos, por lo que no lo vamos a encontrar configurando grandes testeros. El tapial, también tiene poca incidencia visual, aunque sabemos de su uso en la mayor parte de los muros de Torre Águila. Por último, el opus signinum, u hormigón hidráulico ${ }^{4}$, lo vamos a encontrar de manera intensa para realizar pavimentos así como elemento impermeabilizante de aljibes y/o piscinas.

Opus caementicium. Lo primero que debemos decir acerca de esta fábrica, es que aparece casi siempre formando parte de las cimentaciones. Podemos distinguir dos tipos de hormigón. El primero de ellos presenta una textura muy compacta, con árido de grano fino -arena de río, sin duda- y una tonalidad típica, gris perla. Al ser observado con detenimiento

\footnotetext{
4 Denominamos opus signinum, al mortero realizado a base de arena, cal y material cerámico machacado, lo que le da su característico tono rojizo. Por hormigón hidráulico entendemos aquél que se elabora con cal, arena -tipo puzzolana- y agua, y cuya coloración definitiva es de tonalidad grisácea.
}

comprobamos que aparecen, entre el árido, pequeñísimos nódulos de cal. En cuanto a los caementa, son de tamaño pequeño, cantos de río mezclados con esquirlas de piedra, obtenidas durante el proceso de talla de las mismas. Tiene una gran dureza.

El otro tipo de caementicium, también es de buena calidad; presenta un mortero más arenoso que el arriba descrito. Los caementa son de cuarcita, irregulares y aparecen mezclados con pequeños cantos de río. Este tipo ofrece menor solidez que el anterior.

Respecto a la técnica constructiva, se observa que, al no aparecer casi nunca visto, configurando paramentos, no se ha documentado en ningún punto el empleo de encofrado. Esto es debido a que se circunscribe a los fundamentos de los muros; por ello, la zanja de cimentación de dichos muros, excavada en la tierra, desempeña las funciones de encofrado.

Otra forma de empleo del opus caementicium es como núcleo de muros con cara vista de opus incertum.

Encontramos opus caementicium, por ejemplo, en el ambiente interpretado como triclinio de invierno (Rodríguez Martín, 1993). Dicha habitación se construyó tras arrasar el establecimiento rural del s. I. d. C.. (Fig. 2). Aquí documentamos el empleo de opus caementicium en las cimentaciones. El sistema empleado es casi idéntico al del resto de las habitaciones de la villa adscribible al s. II d. C.. El proceso constructivo comenzaba con la realización de una zanja, en el fondo de la cual se creaba una base de preparación a base de cantos de río trabados con arena. Solía desarrollar unos $10 \mathrm{~cm}$. en altura, mientras que en anchura, suele presentar idéntico grosor que el cimiento que monta sobre ella. El cimiento está ejecutado con mucho cuidado. Se utiliza un mortero de muy buena calidad, de gran dureza, con árido muy fino entremezclado con pequeños, y abundantes, nodulillos de cal; los caementa son de pequeño tamaño. No se evidencian huellas de uso de encofrado de tablones de madera, por lo que todo parece indicar que fue la propia pared terriza de la zanja, la que desempeñó tales funciones.

En las habitaciones correspondientes a la villa del s. IV, observamos que, nuevamente, el caementicium forma parte esencial de las cimentaciones. En este caso el proceso varía ligeramente. Obviamente, las nuevas estructuras se construyen amortizando la villa levantada con anterioridad. Por ello, arrasan cuidadosa y sistemáticamente, todas las habitaciones precedentes. Por ejemplo, en el ambulacrum junto al 
ambiente octogonal polilobulado, se aprecia como las paredes de tapial, ricamente decoradas con estucos pintados, de la villa precedente, fueron "taladas" y volcadas. Sobre ellas se niveló con arena, tras lo cual se procedió a realizar una zapata; esta suerte de zapata, tiene una altura de $60 \mathrm{~cm}$. y está aparejada con cantos de río trabados con tierra, excepto en la zona de contacto con el muro, propiamente dicho, donde aparecen cogidos con mortero. Hay que añadir, que la zapata es más ancha que el muro que monta sobre ella.

El sistema de cimentación es muy interesante, porque releva el profundo conocimiento que tienen, los habitantes de la villa, de las crecidas del río Guadiana. Esto explicaría la gran altura y anchura de la zapata, ya que su fin era aislar el muro de hormigón de las crecidas del río ${ }^{5}$. Además, se perfila otra motivación para construir así el cimiento. Esta técnica tiene la virtualidad de permitir un cierto movimiento -o pandeo- del muro ante la impetuosidad de las aguas, o simplemente, por el cambio de la consistencia del terreno (de húmedo a mojado, y viceversa). De esta forma se evita la rigidez del cimiento y con ello, un posible agrietamiento de la construcción.

Opus incertum. Al igual que se documenta con el caementicium, el incertum se apareja de dos maneras. El primer tipo se caracteriza por presentar, en su cara vista, grandes piedras, de forma trapezoidal, más o menos irregulares (Fig. 3.1). Las piedras se colocan ordenadamente, por su lado más largo, configurando una suerte de hiladas. Estas hiladas, a su vez, forman tongadas. Las tongadas se distinguen nítidamente, ya que están separadas entre sí por verdugadas de ladrillo; este hecho permite medir la altura, o grosor, de dichas tongadas. Cada banda latericia está formada por dos hiladas de ladrillo $\mathrm{y}$, como acabamos de decir, su funcionalidad es -entre otrasel corregir el nivel de la tongada, regularizando el contacto entre una y otra.

El otro modo de construir en opus incertum se diferencia del anterior en que las piedras que configuran la fábrica son de considerable menor tamaño que las otras (Fig. 3.2). Además, morfológicamente, tienen una marcada tendencia al paralelepípedo; por ello nos recuerda especialmente a los mampuestos.

5 Aún hoy día, incluso con la regulación del cauce mediante el sistema de embalses, las crecidas alcanzan considerable altura. En caso de que la riada no llegase físicamente hasta allí, sí crecería el nivel freático, máxime, si tenemos en cuenta que la villa se asienta sobre un terreno de naturaleza aluvial, lo que le confiere gran permeabilidad.
El núcleo de estas fábricas siempre es opus caementicium. Sin embargo, podemos puntualizar dos asociaciones: el primer tipo de hormigón descrito, aparece siempre formando parte de la primera manera del incertum; y, lógicamente, el segundo prototipo de caementicium se presenta agrupado al segundo modelo de opus incertum, recordando su cara vista más que un incertum, un caementicium careado.

Debemos decir que presentan, en ambos casos, unos acabados muy cuidados; sin embargo, jamás fueron superficies que quedaran vistas pues luego se cubrían bien con estucos decorados con pinturas, bien con placaje de mármol.

Uno de los ejemplos más vistosos corresponde al triclinio de verano -aestivus locus- (s. II d. C.). Se trata de una habitación semisubterránea, a la que se accede mediante una escalera. Los muros están aparejados en opus incertum, con elementos de tendencia trapezoidal y de tamaños medianos y grandes. Se trata de la cara vista de un núcleo de hormigón.

Respecto al sistema de construcción, sabemos que el muro se levantó de la siguiente manera. Se hizo una zanja, a modo de terraplén; a cierta distancia del desmonte $^{6}$ y se dispusieron las piedras del incertum, ordenadamente y por hiladas, cuidando de guardar el nivel y la horizontalidad de la fábrica. Estas piedras, en principio están cogidas entre sí con mortero. Luego, dependiendo del grosor del núcleo del muro, se recurre a la ayuda de un parapeto de madera para que aguante bien la presión ejercida por el vertido del caementicium. Dicha colada de hormigón traba con la superficie prominente de la parte trasera de las piedras, configurando así un unicum. Esto es lo que se denomina tongada $\mathrm{y}$, en el caso del triclinio de verano están perfectamente señaladas por la presencia de una verdugada de ladrillos, compuesta por dos hiladas. Como remate, la fachada estuvo chapada con mármoles, de los que son prueba evidente las mortajas de las grapas de garfio que sujetaron las placas de mármol con que estaba embellecida la habitación.

El opus incertum es empleado, nuevamente, en la construcción de la nueva villa del s. IV. Por ejemplo, en la habitación tetraconca, se realizan los muros en opera incerta, por ambas caras y revisten un núcleo de hormigón. Este, es menos compacto que el arriba descrito porque en su composición se aumenta el porcentaje de arena en perjuicio del de cal.

\footnotetext{
${ }^{6}$ Desconocemos el grosor del muro completo, por hallarse la habitación en perfecto estado
} 
Opus testaceum. Lo primero que debemos destacar respecto de esta técnica es que en Torre Águila no hay ningún muro $o$ habitación aparejada exclusivamente en ladrillo. Esto puede ser debido a que, históricamente, la villa ha sido cantera de material latericio para las gentes del lugar (Rodríguez Martín, 1993). Sin embargo, arqueológicamente, se observa total ausencia de muros enteros aparejados con este material. No obstante, y como se ha señalado más arriba, se emplea con profusión el testaceum. Su finalidad es la de nivelar superficies irregulares, enrasando el lecho de recibimiento y regularizar el recrecimiento del muro. Por ello aparece siempre en verdugadas de dos hiladas, con ladrillos dispuestos a soga. En la fábrica se aprecia un especial cuidado en llagas y tendeles. Están unidos entre sí con un mortero de idénticas calidades que aquel empleado para trabar el núcleo del muro.

Donde más ladrillos aparecen es, como es lógico, en el área de las termas. Aquí son de menor tamaño, casi como es preceptivo, y no presentan tanta regularidad como los de los muros. En las termas configuran las pilae y arcuationes de apoyo de la suspensurae, así como suelo del praefurnium. También aparecen configurando un sistema de doble pared de tipo panelado: los ladrillos forman triángulos que se superponen unos a otros (Fig. 4).

También aparecen ladrillos, configurando las jambas y un arco rebajado, o platabanda, perdido, en la reforma y cambio de uso del aestivus locus.

En las dimensiones de los ladrillos se aprecia bastante regularidad, pero también se constata la existencia de medidas no demasiado canónicas. En ningún caso se aprecia que las piezas hayan sido recortadas ni, en apariencia, reutilizadas. Por ello, nos inclinamos a pensar que, como debe tratarse -sin género de duda- de una producción propia de la villa, las medidas no siguen estrictamente el patrón estándar, que tenemos recogidos en edificios públicos de la capital lusitana (Durán Cabello, 1998 y 2004, CD). Enlazando con esto último, podemos afirmar que la producción de ladrillos, ímbrices y tejas, se realizaba en villa. Normalmente el proceso era como sigue. Una vez que se extraía la arcilla, se pasaba a diferentes piscinas donde reposaba y se decantaban las impurezas de mayor volumen. Tras ello, se solía depositar en el almacén. Estos poseían, generalmente, silos excavados en la tierra donde la arcilla se conservaba, fresca y sin apenas perder humedad, hasta que fuese preciso utilizarla. Llegado este momento, se volvía a amasar, aunque el término más correcto es el de "pisar". El paso siguiente consistía en cajear los ladrillos con un molde de madera, de forma rectangular, sin fondo, que se conoce como forma. Una vez que se realizaba esta operación, se dejaban secar al sol durante varios días -en torno a una semana, más o menos- periodo durante el cual los aún lateres perdían el exceso de agua para poder ser sometidos al proceso de cochura ${ }^{7}$. Los hornos empleados eran muy similares a los que se conocen para usos cerámicos. Las dimensiones varían según se trate de una producción industrial o de una artesanal, esto es para cubrir las necesidades privadas de la villa ${ }^{8}$. Durante el proceso de cocción se alcanzaban temperaturas muy altas, que podían oscilar entre 600 y 800 grados. Una vez acabada la combustión, se dejaba enfriar el horno, lo que podía durar varios días -dependiendo del tamaño- tras lo cual se extraía la hornada y ya estaba lista para utilizar o para almacenar'. Sabemos por fuentes arqueológicas y literarias, que era un trabajo muy indicado para mujeres y niños $-\mathrm{y}$ aún se comprueba en la actualidad en países tercermundistas-. En el caso de Torre Águila, tenemos pruebas de que en el proceso de fabricación de tejas y ladrillos participaban niños. Efectivamente, así lo demuestra la huella de un niño (Fig. 5.1) que quedó impresa en la arcilla fresca del ladrillo ${ }^{10}$. Junto a esta impronta de reducidas dimensiones aparecen pisadas de perro, hecho este muy bien conocido.

El opus testaceum también se reservaba para las roscas de los arcos. Confirmando esto, se conserva el arranque de un arco de medio punto, aparejado en ladrillo.

En las últimas fases de pervivencia de la villa, el material latericio es profusamente amortizado. En efecto, las tumbas tardías recuperan de las habitaciones ya en vías de abandono, las tegulae e imbrices, de las cubiertas ya caídas así como ladrillos para realizar el fondo de dichos enterramientos ${ }^{11}$. Todos ellos presentan unas dimensiones muy homogéneas entre sí.

${ }^{7} \mathrm{Si}$ no se dejaban "sudar" los ladrillos y tejas para perder el exceso de agua, al ser sometido a cocción, se agrietan y salen defectuosos.

${ }^{8}$ Para más información ver (Laubenheimer y Le Ny, 1999).

9 Tenemos datos en Torre Águila que nos hablan del almacenaje, a pequeña escala, de material constructivo. No podemos afirmar, rotundamente, que fuese con fines previsores (subsanar posibles desperfectos) o que estuviesen dispuestos en las inmediaciones de la zona a reformar y allí se quedaron porque se abortó el proyecto (Rodríguez Martín, 1993).

${ }^{10}$ Actualmente este ladrillo no existe, ya que fue destruido en el transcurso de las obras de consolidación y restauración de los muros de la villa.

${ }^{11}$ En su afán de reutilizar, emplean como cubierta de los enterramientos muros caídos de ladrillo. 
Encontramos ladrillos en las jambas del nuevo acceso al estivalia. El dintel no llegó hasta nuestros días seguramente fue robado por su material ${ }^{12}$-. Las dimensiones de estos ladrillos son bastante dispares, lo que apunta, por un lado, a la producción doméstica de la villa; y, por otro, al empleo de material amortizado de la fase precedente. Esta reforma se realizó entorno a fines del s. I y principios del s. II.

Nuevamente hallamos el empleo de material latericio configurando arcos de una especie de criptopórtico que pondrían en relación las termas y el peristilo. Esta construcción data entre fines s. I y principios del s. II.

También encontramos ladrillo configurando las arcuationes que soportaban la suspensura en las termas de la villa del s. IV. Igualmente en esta fase debemos subrayar el uso, muy extendido, de opus incertum jalonado por verdugadas de ladrillo.

Tapial. Este debió ser el modo de construcción más extendido en la villa. Por lo endeble de su consistencia, apenas si han llegado restos hasta nosotros. Sin embargo, tenemos constancia de su uso en un muro que aún queda parcialmente en pie, y que nos sugiere cómo pudo ser el sistema de construcción. Sobre la cimentación, de $c a .75 \mathrm{cms}$. de altura, se recrecía el muro realizado en barro compactado. Con el fin de ocultar a la vista lo pobre del material, estas paredes se enfoscaban $y$, posteriormente, se decoraban con estucos pintados, de los que se poseen abundantísimos restos ${ }^{13}$ (Fig. 6).

El sistema de construcción del tapial ha pervivido hasta el presente, de ahí que sea fácilmente comprensible su modo de ejecución. Se realiza con tierra, agua y fibras vegetales; estas funcionan como desgrasantes y dotan de cohesión a la mezcla. La mezcla se hace bien pisándola, bien removiéndola

${ }^{12}$ Históricamente la villa ha sido saqueada con finalidad de encontrar material cerámico, como revela el hecho de aparecer los pavimentos rotos por la búsqueda de ladrillos de arcuationes y pilae de los hipocaustos, por ejemplo (Rodríguez Martín, 1993).

13 En efecto, cuando se va a construir la villa del s. IV, arrasan algunas de las habitaciones del periodo precedente. Estos muros son talados a partir de cierta altura (sobre la zapata de hormigón) y sus restos, con sus decoraciones pictóricas y sus reversos preparados para la adhesión al paramento, fueron empleados como escombro de relleno para preparar una nueva superficie constructiva para la gran villa del s. IV. El hecho de que fueran talados nos habla de la naturaleza del material constructivo así como los propios muros caídos y formando parte del relleno de colmatación previo a la construcción de los nuevos ambientes de Torre Águila. con largas palas, a modo de remos. Una vez que estaba dispuesta se dejaba perder el exceso de agua y ya estaba lista para utilizar. Dado lo plástico del material, los muros recrecidos en tapial solían estar fortalecidos mediante la inclusión de postes de madera, dispuestos cada cierto trecho; para dar homogeneidad a sus caras vistas se recurría a un encofrado de madera y, una vez dispuesto en fábrica se dejaba secar un poco $y$, posteriormente, se retiraban los tablones y se dejaba secar al sol. Una vez fraguado del todo, se aplicaba un enfoscado de cal y arena, con la finalidad de aislar e impermeabilizar el muro así como para subsanar alguna pequeña imperfección. Posteriormente, recibía las capas preparatorias de mortero así como un entramado de cañas para darles mayor fuerza y cohesión; sobre la última de estas capas se disponían los estucos pintados.

Los restos que mejor conocemos pertenecen al s. II y han llegado hasta nosotros en muy buen estado debido a una circunstancia peculiar. Los muros de tapial, decorados con pinturas, fueron, sistemática y cuidadosamente, abatidos con el fin de utilizarlos como material de relleno, junto con sus plintos de hormigón. Sobre este nivel de colmatación, se procedió a nivelar con tierra y es a partir de esta cota que se construye la villa del s. IV. Sin embargo, de la villa del s. IV apenas sí tenemos ejemplos.

Opus quadratum. Como se ha dicho, su empleo es muy escaso, y en muchas ocasiones, viene marcada su utilización por necesidades técnicas. Concretamente para configurar esquinas, dotándolas de regularidad y resistencia tectónica; también para soportar grandes empujes, como se ve en los anclajes de las prensas así como para sujetar el cigüeñal de la prensa. Sólo hay un caso en que aparezcan los muros aparejados en quadratum, es en la bodega (Fig. 7).

En primer lugar, debemos hablar de la naturaleza del material. Los sillares fueron extraídos de las canteras de Guadajira, montes de Lobón y Lácara ${ }^{14}$. Se trata de una caliza local, relativamente blanda, lo que facilita su desbaste y alisamiento. Esta versatilidad es, al mismo tiempo, su mayor inconveniente, ya que se exfolia fácilmente y sufre una fácil erosión.

Tenemos recogidos varios sillares trabajados en piedra granítica, de grano fino, y marcada tonalidad gris perlado. Respecto a su posible procedencia, se abren dos posibilidades: por un lado, los afloramientos graníticos de la zona de la Nava de

14 Junto a las canteras romanas de Lácara, se han podido documentar los hornos de cal. Hornos que también se encuentran en las inmediaciones de La Garrovilla (Gorges y Rodríguez Martín, 2000, 124-125). 
Santiago, o, las canteras romanas localizadas en las afueras de La Garrovilla ${ }^{15}$. Este granito presenta una gran dureza, y su calidad se refleja en el acabado uniforme de sus superficies.

En lo referente al ritmo de colocación de los sillares, sólo tenemos una habitación para documentar este aspecto técnico y es, como ya se adelantó, el granero. En sus muros vemos que los sillares se disponen regularmente por hiladas, siendo las cuatro primeras de una menor altura, concretamente $47 \mathrm{~cm}$. (algo más de pie y medio); se emplazan, preferentemente, a soga, aunque aparece a tizón, para enganchar la fábrica en las esquinas.

La ejecución de los bloques muestra un cuidado en el rebaje y alisado de las bandas laterales, de manera que parecen, en algún caso, líneas de anathyrosis.

Respecto a su colocación en fábrica, no poseemos huellas de uso que nos hablen del empleo del ferrei forficeps o de la castañuela (Adam, 1989, 50-52; Ginouvès y Martín, 121-122); tampoco quedan huellas de canales para el empleo de cordajes. Por todo ello, suponemos que, en el caso concreto del granero (vide infra) se utilizaron rampas de tierra para su transporte y la definitiva colocación en obra se hizo con ayuda de palanca, como evidencian algunas muescas inconfundibles.

En cuanto a las herramientas empleadas en su escuadramiento y desbaste, no podemos precisar nada por lo lavado de sus superficies, aunque suponemos que debieron ser las propias de cantero, ampliamente atestiguadas en grandes monumentos aparejados con fábrica de sillares, como el teatro emeritense donde está ampliamente reconocido el uso de la escoda y la cucarda (Durán Cabello 2004, 128, n. 3 y 4).

El único caso en que aparecen los sillares aparejados, configurando paramentos, es en el ambiente interpretado como bodega, que perteneció al establecimiento datado en el s. I. En la fase siguiente, no fue reutilizado ni sus materiales amortizados, lo que es mucho más extraño, pero nos señala un dato muy significativo: la falta de costumbre de construir con este aparejo, de manera que se oblitera el ambiente, rellenándolo con tierra. Sólo la parte superior del muro sirvió como cimiento a la construcción de un corredor y de dos estancias que formaban parte de un bloque de cubicula de la villa del s. II.

Del s. II aparece en el lagar, primero se excava y se hace un muro de incertum alternando con pilastras de granito. Está aparejado de tal manera que los sillares

\footnotetext{
${ }^{15}$ Estas canteras son unas de las que abastecieron las obras públicas emeritenses.
}

coinciden siempre con los anclajes de la prensa (Fig. 8). Esto es en el nivel de cimientos. Posteriormente, en el s. IV se reaprovecha el muro este para hacer un aljibe de vino con capacidad para 18 mil litros.

Opus signinum. Aparece usado como revestimiento hidráulico, así como configurando diversos tipos de pavimentos. Encontramos varios tipos de signina. En primer lugar se documenta un hormigón hidráulico consistente, de granulometría fina y de característico color rojizo oscuro. Suele aparecer aplicado en finas capas, cuyo grosor oscila entre los 2 y los $2^{\prime} 5 \mathrm{~cm}$., como en la piscina del tepidarium.

Otro tipo de signinum es aquél que ofreciendo, también, gran consistencia, revela una ejecución menos cuidadosa, como revela el tamaño de los fragmentos latericios machados. Se aplica en capas más espesas -seguramente por su gruesa granulometría- que alcanzan los $3 \mathrm{~cm}$. Se caracteriza por un típico color rojizo-rosáceo intenso. Aparece, en ocasiones, sobre el anteriormente descrito, en la superficie y escalones de las bañeras de las termas.

Hay que señalar, que en las termas de la villa del s. IV, se emplea el signinum en los pavimentos. Los caementa son de tamaño considerable, lo que hace que su consistencia sea menor; si a esto unimos que la proporción de cal no es tan alta como en la fase precedente, el resultado es una superficie llena de "desconchones". Su coloración es rojiza.

Siguiendo con las termas, en las bañeras no se utilizó el opus signinum en principio, porque estaban chapadas con mármol. En un momento posterior, al repararlas, se revistieron con hormigón hidráulico. Este tiene caementa más fino que los de los pavimentos, así como color grisáceo. Tiene buena consistencia.

Pero el ejemplo más ilustrador de la pervivencia y uso de la villa lo constituye la habitación de ábsides contrapuestos, perteneciente a la construcción del s. IV. En ella se han podido atestiguar un total de cinco fases sucesivas de pavimentos de opus signinum. Conforme se superponen son cada vez de menor calidad y revelan cierta impericia. Impericia que se hace patente en el tamaño de los fragmentos de ladrillo machacado, que son cada vez más grandes y en el mortero, que cada vez posee menos cal, por lo que se desintegra con mayor facilidad. Además, cada capa de signinum es cada vez más gruesa que la anterior. Buena prueba de ello es que desde el suelo de uso, el inicial del s. IV, hasta el último nivel, se recrece un total de $50 \mathrm{~cm}$.

Esta secuencia de pavimentos nos está hablando de una zona de la casa muy transitada, posiblemente una zona de paso, o estar, que tuvo mucho desgaste, y que 
siempre continuó en utilización, lo que explicaría la necesidad de tenerla siempre en buenas condiciones. $\mathrm{Su}$ cronología va desde el s. IV, momento en que se construye toda la villa, hasta el s. V.

Por último, queremos mencionar el lagar, donde el pavimento y los labra, están revestidos con hormigón hidráulico (Fig. 8). En el aljibe se ha podido establecer dos épocas sucesivas, atestiguadas por las dos capas de signinum. La más antigua, esto es la inicial del s. II, muestra un hormigón fino, pulido, de color rojizo-rosáceo oscuro y presenta un grosor de 2 $\mathrm{cm}$. (Fig. 9). En la fase siguiente, se aprecia un mortero mucho más tosco, menos cuidado, casi sin pulir y de característica tonalidad rojizo-teja. El grosor de esta capa es de $3 \mathrm{~cm}$.

El pavimento del lagar muestra en superficie color negruzco, como sucio. Por la rotura del pavimento se ha podido comprobar la realización de -al menos tres fases consecutivas de signinum, de las que la más profunda, se muestra menos alterada y evidencia un color rojo vivo. El motivo de la coloración del último pavimento reside en el uso que tenía la sala: prensado de las aceitunas. Durante este proceso, se produce un desperdicio viscoso, negruzco, conocido como amurca (Rodríguez Martín y Gorges, 1999: 411) que es el responsable del cambio de tonalidad.

\section{LAS DIFERENTES PARTES DE LA CONSTRUCCIÓN.}

En este apartado trataremos de hacer una recopilación de las principales características de los distintos elementos constructivos: cimentaciones, pavimentos, muros, vanos y cubiertas.

Cimentaciones. Lo primero que hay que subrayar es que el sistema de apear muros no varía, al menos de manera sustancial, entre las distintas fases de ocupación del lugar. Por ello vamos a repasarlas, cronológicamente. Pero antes de pasar a ello, queremos puntualizar que estas maneras de construir han sido constatadas en todas la villae de la zona de las Vegas del Guadiana.

Siglo I.- En los escasos restos estructurales pertenecientes a este momento, observamos que el sistema consiste en excavar una zanja y disponer una capa preparatoria a base de cantos de río, de tamaño, mediano/grande, trabado con arena, también de río (Fig. 10). Sobre este nivel de asentamiento se desarrolla en altura la cimentación, propiamente dicha, hecha a base de piedras trabadas con mortero de cal. La anchura de las fundaciones es de ca. 70/80 $\mathrm{cm}$., y sobresalen con respecto al muro, que presenta una anchura de $50 \mathrm{~cm}$.
Existe una excepción, y esa es la de la habitación interpretada como granero. Al ser esta una estancia subterránea, y estar construida en opus quadratum; la hilada inferior del muro se apea directamente sobre la terraza fluvial, esto es, un suelo terroso. No existe zapata ni nada similar.

Siglo II.- La villa se construye sobre los restos de la precedente. En algún caso se amortizan los muros anteriores como cimentación de los nuevos paramentos. Esto se constata en la zona de corredor así como en dos estancias que formaban parte de un bloque de cubicula de la villa. Se asientan aprovechando la parte superior de los muros de quadratum de la bodega de la fase precedente.

En general, observamos que se realizan las cimentaciones excavando una trinchera, al fondo de la cual se dispone una o dos hiladas, a veces mucho más potentes ${ }^{16}$, de cantos de río trabados con arena. Sobre ella discurre una zapata realizada en hormigón con caementa de tamaño mediano, de piedra calcárea y arenisca, así como con cantos de río (Fig. 11). El mortero es muy fino y rico en cal, lo que le otorga una extraordinaria dureza.

Un caso singular lo constituye la cimentación del lagar. En él se recurre a un sistema, que podríamos denominar como mixto, ya que utiliza hormigón y sillares. Esto es, sobre la capa de preparación de cantos de río, se recrece la cimentación propiamente dicha, realizada en caementicium. Sin embargo, este hormigón aparece reforzado de trecho en trecho, con la incluso de sillares. Esto se constata en tres puntos que, casualmente, coinciden con las zonas que van a sufrir más presión por el prelum: el anclaje, el contrapeso y, en menor medida, la zona de prensado (Rodríguez Martín, 1988, 223 ss.).

Siglo IV.- La principal diferencia con la fase precedente es que se construye derruyendo la casi totalidad de las construcciones anteriores. Para recrecer el terreno y nivelarlo, se procede al desmantelamiento sistemático de los muros, que son "talados", como se ha mencionado anteriormente, y cubiertos con arena. Sobre esta nueva superficie se fundan los nuevos muros. Las zapatas son muy potentes, llegando a alcanzar $c a .60 \mathrm{~cm}$. de altura; están todas aparejadas con cantos de río trabados con barro, excepto la última "hilada", la de contacto con el muro en sí, que aparece con los cantos cogidos con mortero.

${ }^{16}$ En el caso de que la capa de cantos de río sea muy potente, se observa que toda ella está trabada con barro, excepto la zona de unión con el cimiento; esa última hilada muestra los cantos de río cogidos con el mismo mortero que el del hormigón. 
Sabemos que hasta el s. VI, se seguirá empleando la zapata para el apeo de los muros y así lo demuestra el edificio NE. A partir del s. VIII deja de construirse con zapata.

Muros. Hay que decir que han llegado muy arruinados a nosotros, y no sólo en el caso de Torre Águila, sino en muchas de las villas de su entorno como se explica más adelante.

Respecto a la técnica edilicia dominante, podemos decir que debió ser el tapial y de presencia casi parecida, el opus incertum. En cuanto al grosor de los muros, también se ha podido documentar un gran incremento de sus espesores. Pero todo ello lo veremos seguidamente.

Siglo I.- Lo que mejor conocemos es el granero y como ya se ha expresado, está aparejada en quadratum, bastante cuidado y regular. Del resto, como se conoce tan poco, apenas sí conocemos exclusivamente los fundamentos. Por los exiguos restos conocidos, se aprecia que las paredes debieron construirse en una suerte de mampostería o incertum, por no se puede decir nada más específico sobre el particular.

Siglo II.- Se fabrican preferentemente en tapial, por la rapidez de ejecución de la obra, por lo económico del material y por su fácil localización. Ya hemos dicho que luego esos toscos acabados eran rematados con enfoscados y posterior decoración de estuco. Se asentaban, siempre sobre un alto plinto de hormigón y este sobre la zapata preparatoria, ya descrita. Con este modo de construir se evitaba que subiese por capilaridad, la humedad a través de las paredes. Apenas sí conocemos algo más de $25 \mathrm{~cm}$. de tapial, in situ, sobre su plinto, ya que cuando se construyó la villa del s. IV, los muros fueron cortados. Gracias a que han quedado caídos junto a sus cimentaciones y se han podido recoger hasta las cornisas molduradas de estuco, se ha podido averiguar la altura interna de alguna de esas habitaciones, que era cercana a los tres metros, más o menos (Rodríguez Martín, 1993).

Junto al tapial, está muy bien representado el opus incertum, que por lo cuidado de la fábrica, casi parece una mampostería. Ya se ha dicho que el de esta fase está ejecutado empleando grandes piedras de tendencia trapezoidal, colocadas por su lado más largo, bien careadas en fachada y en su trasera, puntiagudas e irregulares, para trabar así mejor con el mortero del hormigón del núcleo.

Se disponían siempre por su lado más largo, que hacía las veces de lecho de puesta.

A pesar del cuidado que revela la obra, era preciso corregir los pequeños desvíos respecto a la cota horizontal. Para ello se utilizó la misma solución que estaba ya tan experimentada en Emerita: nivelación de tongada mediante la colocación de verdugadas de ladrillo. Esta solución es muy atractiva, visual y cromáticamente hablando, pero este razonamiento jamás se tuvo en cuenta en la Antigüedad, pues en aquel entonces, estaban condenadas a no ser vista por el revestimiento de mármol o por la decoración de estuco pintado.

Siglo IV.- En esta fase tuvo que ser, de nuevo, el tapial, la técnica muraria más extendida, pese a que apenas si han pervivido muros que así lo avalen. Dicho esto, también tenemos que hacer notar que, la técnica de construcción no debía ser muy diferente al modus operandi, del s. II.

El otro tipo más extendido de prototipo constructivo es una especie de opus incertum, aparejado con caementa de tamaño mediano y pequeño. Los caementa aparecen trabajados y por lo reducido de su tamaño, nos recuerdan a pequeños mampuestos.

Vanos. Es lo que peor conocemos, dado el grado de destrucción de la villa.

Siglo I.- Por los pocos restos que quedan, nada conocemos sobre puertas y ventanas. Sin embargo, sí sabemos que a la habitación subterránea se accedía mediante unas empinadas escaleras. No podemos aventurar la luz del vano de acceso, pero no debería ser demasiado estrecha si tenemos en cuenta su función de almacenaje.

Siglo II.- Pese a que de este momento ya conocemos una superficie mucho mayor, no se ha conservado ningún alféizar de ventana, porque casi todo lo que ha llegado hasta nuestros días son los cimientos. Únicamente conocemos la existencia de un tragaluz que iluminaba el aestivus locus. En otros casos si podemos saber la anchura de las puertas, gracias a que ha quedado la huella del umbral, que suele de 80 $\mathrm{cm}$. $c a$. Esto es reconocible en el área termal, en ambos triclinia y en el bloque de cubicula. Como es lógico, el paso con mayor luz se da en la habitación con más prestigio, el triclinium; en los cubículos, las puertas son, considerablemente, más estrechas. En cuanto al área termal, decir que lo conservado es, en la mayoría de los casos bajo el nivel de suspensura.

Siglo IV.- De este momento constructivo conocemos muchos más pormenores. En líneas generales podemos avanzar que, en este caso, han sobrevivido más vanos del área noble de la villa, que del sector privado, pues sólo intuimos dónde se desarrollaron los bloques de cubicula.

Técnicamente, debemos decir que se constata el empleo de sillares en la construcción de jambas, para 
dotarlas de mayor fuerza y regularidad. En la inmensa mayoría de los casos han sido cuanto menos desplazadas, y en la mayoría de los casos robadas para su reutilización.

En el área pública tenemos vanos de gran luz, que nos subrayan junto con las estancias, una composición arquitectónica muy escenográfica (Fig. 12). Así el acceso desde el área abierta al NW del conjunto noble, arroja una luz de prácticamente 5 metros. Este paso da acceso, a su vez, a izquierda y derecha, a una habitación de ábsides contrapuestos, o doble absidadas. Para llegar a alguna de estas salas simétricas, el vano era de casi $2 \mathrm{~m}$. de ancho. Tras ellas se llega a una estancia de paso entre las anteriores y la crujía del peristylum; obviamente, tiene un vano apenas sugerido, puesto que su función es ésa: poner en contacto un área con otra. Una vez en el pórtico del peristilo, hacia el sur, se llegaba a la primitiva habitación tetraconca, cuyo acceso, posteriormente clausurado, era considerable: ca. 4'5 m.. Hacia el ala norte, aparece una puerta de una estancia, identificable con un cubículo del dominus, por su ubicación; presenta un vano de algo menos de $1 \mathrm{~m}$. Mención especial merece la estancia situada en el ángulo norte del pasillo, de planta octogonal polilobulada. Su antigua entrada se realizaba a través de un largo y ancho corredor, que desembocaba en un acceso de $1 \mathrm{~m}$. de ancho (aprox.); En este momento, esta sala singular estaba en contacto con una habitación perteneciente al bloque de cubicula nobles que se desarrolla en torno al patio. Hay que subrayar un detalle que, nuevamente, nos habla de la escenografía de la composición. El paso a la habitación, en planta, es abocinado, para conservar, de esta manera la composición alterna de exedras y hornacinas rectangulares. Item más, cuando el tránsito se hace en sentido inverso, esto es desde el supuesto cubiculum al salón, se hace por un paso muy estrecho que incrementa el efecto de grandiosidad del aula central. Sin embargo, como se puede comprobar, en el primer momento de uso de este sector de la villa, el aula central no tiene acceso directo desde el peristilo; para acceder a él debía recorrerse, forzosamente, el pasillo en sentido inverso. Dicho pasillo conserva una longitud de 13 m. (ca.), distancia en la cual se documenta la existencia de un paso a la crujía del patio. Por ello, se hizo una reforma, y esta consistió en perforar la exedra que hacía ángulo con el peristilo, lo que implicó, a su vez, una reforma parcial en el cubículo anejo a la sala, cuya esquina sureste pasa a ser ahora una suerte de chaflán en curva. La nueva puerta tiene exactamente la misma luz que la exedra: casi 1'5 m. La creación de este nuevo paso supuso el cierre de la puerta originaria.
Conocemos, también, la entrada al salón de las termas, que se realiza desde un vestibulum; es una puerta estrecha, lógicamente, para evitar la pérdida de calor de todo el conjunto. El paso hasta la piscina del frigidarium es amplio, cosa absolutamente normal. De la zona caldeada no han quedado restos de las puertas, porque fue saqueada sistemáticamente para beneficiar el material latericio.

Respecto al sector industrial, donde se ubicaron el lagar y la almazara, conocemos ahora su vano de tránsito y, como era de esperar, es un elemento amplio y diáfano, destinado a facilitar el trasiego de material para las labores que allí se realizan (llevar la uva y/o la aceituna; sacar los desperdicios de la prensada; el remanente de esteras para preparar las prensadas, etc.).

Siglo V.- En esta época se construye el conjunto situado al noreste del aula octogonal, muy arrasado por la necrópolis. En él han quedado huellas de tres puertas, con el arranque de jambas. Así, la entrada al ábside presenta algo menos de $1 \mathrm{~m}$. de anchura. Respecto al acceso al conjunto formado por el salón mixtilíneo, a cuyos lados este y oeste se abren sendas piscinas con un canal visto que las pone en contacto, el paso es complejo puesto que no ofrece acceso directo. Primero se pasa a una especie de vestíbulo a través de un paso de casi $2 \mathrm{~m}$. de ancho, que está afrontado al que lleva directamente a la sala y que tiene, prácticamente, la misma luz: algo menos de 2 m. En la cabecera de este salón, hacia el norte, se desarrollaba una estancia octogonal, simple, destruida a nivel de cimentación, lo que nos impide saber cómo se llegaba a ella desde la sala central.

Cubiertas; Son casi tan desconocidas como las ventanas. De ellas no podemos dar sino unas pautas generales, por lo increíblemente escaso de los restos. En efecto, salvo en algunos casos -granero subterráneo, aestivus locus y termas- la mayoría de las estancias tuvieron cubiertas con armadura de madera, de las que no han llegado hasta nosotros.

El granero, dado el nivel de arrasamiento, no permite reconocer si tuvo una cubierta plana, con vigas de madera y un forjado -como parece más lógico-, todo ello recubierto al exterior, no imaginamos cómo.

El aestivus locus, tiene una cubierta abovedada, muy rebajada, ya que está generada por un arco carpanel muy plano. Se realizó con ayuda de cimbra de madera y está aparejada en ladrillos, cuya fábrica se remata mediante un enfoscado. Este pudo ser documentado durante el proceso de excavación (Rodríguez Martín, 1993).

Las termas, pese a estar todas muy arrasadas, sabemos por otros casos que no se emplea armadura 
de madera por el peligro que entraña. Así que se realizan cubiertas abovedas, aparejadas mediante roscas de ladrillos, que suelen configurar canales de circulación de calor y humos, así como por tubuli fittili, de los que -en principio- no hay ningún resto, y cuya misión era la de macizar las cubiertas aligerando el peso.

En el aula octogonal, hubo con casi toda seguridad, una bóveda de arista, Restos materiales de la misma no han sobrevivido pero sí han quedado evidencias de su apuntalamiento. La existencia de esta bóveda se ve subrayada por el grosor que presentan los muros de este salón. Respecto a la naturaleza de su construcción, es posible que se realizase con estuco y las aristas de ladrillo, todo ello ejecutado con el auxilio de cimbra.

Algo similar tuvo que suceder en el aula tetraconca, donde seguramente hubo medias calotas coronando los ábsides, así como en el espacio doble absidado. El sistema constructivo sería parejo al del salón octogonal.

No podemos aventurar cómo serían las cubiertas del edificio creado en el s. V, al NE de la villa porque los restos son muy escasos. No podemos descartar que también se emplease bóveda como cubierta interior, aunque nos parece más probable la presencia de una cubierta de madera con armadura de la misma naturaleza.

Las cubiertas exteriores serían todas, y creemos que durante toda la ocupación del lugar, de tejas y ladrillos, en infinidad de casos reutilizados en la fase subsiguiente. Conocemos bastante bien los de la villa del s. IV porque fueron todos reutilizados en la necrópolis.

\section{LOS SISTEMAS CONSTRUCTIVOS EN LAS VILLAE DE LAS VEGAS DEL GUADIANA.}

Como premisa debemos decir que, las villas de las subcesivae del Guadiana, reúnen unas características especiales (Rodríguez Martín y Gorges, 2000, 135 ss). Son villae intensamente relacionadas con el medio urbano emeritense, lo que las diferencia notablemente de otros asentamientos rurales. Esto propicia, desde el principio, que estas villas presenten unas características arquitectónicas y constructivas que las emparentan de manera directa con las domus urbanas o, periurbanas.

\section{Los materiales de construcción}

En las Vegas del Guadiana se aprovechan de los materiales del lugar para realizar las construcciones, no se recurre a la importación de los mismos - excepción hecha del mármol-. Sistematizando podemos decir que los cantos de río utilizados como caementa y en la base de cimentación, proceden del vecino río Guadiana, así como sus arenas, empleadas como áridos del hormigón, enfoscados u hormigones hidráulicos.

Piedra.- Respecto a la piedra, podemos distinguir varias zonas: unas vienen de los afloramientos de Lobón-Guadajira, Lácara, La Garrovilla-Carrascalejo y Montijo. De Lobón-Guadajira, se extrae una piedra calcárea, blanda, de tipo caleño, muy fácil de trabajar, pero como contrapartida, también se exfolia fácilmente. De Lácara y La Garrovilla, procede una piedra tipo cuarcita, mucho más dura que la anterior, y tonalidad grisácea verdosa. De Carrascalejo procede el granito, que presenta grano muy fino, pobre en mica y de extraordinaria dureza; muestra una característica tonalidad gris perla. Por último, también se extrae piedra de Montijo, donde hay afloraciones de piedra berroqueña.

Mención especial merecen las canteras de la sierra de Carija, que abastecen de piedra caliza, cal y mármol, fundamentalmente, a la ciudad de Mérida.

Cal.- En cuanto a la cal necesaria para hormigones, morteros y pavimentos hidráulicos, conocemos la existencia de hornos en las inmediaciones del poblado de Lácara, y de Garrovilla. Dichos hornos se localizan, en muchos casos, sobre las antiguas caleras romanas.

Arcilla.- Para realizar material cerámico constructivo, se utilizaría la arcilla existente en los alrededores de las propias villae, dado que el territorio, al ser aluvial, es rico en arcillas. De hecho, toda esta zona estaba llena de "barreros" en la primera mitad del s. XX, pero con la expansión de la ciudad, fueron disminuyendo hasta desaparecer.

Madera.- Su presencia debió ser importantísima, ya que todas las cubiertas -excepto, quizá, el granero subterráneo, del s. I, y el aestivus locus- tuvieron un armadura de madera para sustentar la cubierta de tejas planas y curvas. Por la naturaleza del material, por el largo periodo de ocupación de la villa así como por el nivel de saqueo e intento de arrasamiento que sufrió, no queda nada de ellas -ni apenas carbonizadas entre los estratos- porque fueron reutilizadas: bien para las sucesivas reconstrucciones, bien como combustible.

\begin{tabular}{lrr|r} 
ENSAYO DE & SÍNTESIS SOBRE & LAS \\
TÉCNICAS & Y & FASES & CONSTRUCTIVAS \\
OBSERVADAS EN LAS VILLAE & DE & LAS \\
VEGAS BAJAS DEL GUADIANA. &
\end{tabular}


Sistematizamos este apartado haciendo una breve exposición cronológica ${ }^{17}$.

En el s. I d.C. se ve como siguen el mismo patrón constructivo que en Torre Águila, como por ejemplo en la villa de El Pesquero, Las Termas, El Castillo, Balbina, Floriana, Lácara, etc. Esto es, en todas las villae donde se ha podido documentar una fase de ocupación del s. I.

En el s. II, se observa nuevamente el mismo fenómeno que se acaba de exponer. Sin embargo, hay que subrayar que muchas villas no sobreviven $\mathrm{y}$, posiblemente el dominio territorial, pase a engrosar el de otra gran villa. Constructivamente se realizan los muros sobre zapatas de cantos de río trabados con barro sobre los que se asienta el cimiento; sobre, sobresaliendo a modo de plinto, o zócalo, se recrecían los muros en tapial. En otros casos, para las zonas donde las cubiertas debieron ser más pesadas, que coinciden seguramente con el área noble, se aparejan los muros en opus incertum. El hormigón de esta época es muy duro, compacto, de caementa mediano/grande, y rico en cal. En cuanto al signinum, es de aspecto muy fino y pulido, de color rojizo rosáceo, con grano muy menudo, fruto de la buena ejecución del mismo.

Las villas del s. IV ofrecen la misma uniformidad constructiva que las villas construidas en la fase precedente. La única gran diferencia es la estructuración de la villa así como su repertorio decorativo. Todas constan de termas, peristilos, grandes salones de recepción, cubículos y demás estancias. En algunas de ellas, como por ejemplo en Las Termas, se documenta una fase tardoantigua, evidenciada por sus restos decorativos así como por presencia de necrópolis; lo más importante es que aparecieron restos de canceles, relacionados,

\footnotetext{
${ }^{17}$ De todos los datos que se exponen, tan sólo proceden de excavación los obtenidos para las villas de Torre Águila, La Cocosa, Las Tiendas y El Pesquero. El resto de las mencionadas se conocen por prospección y, por desgracia, posteriormente han sido arrasadas en los trabajos de explanación de las fincas para puesta en regadío, como es el caso de Las Termas, la Balbina, Torre Águila II, Los Torrejones, Floriana, etc. En otras ocasiones, las villas aparecen seriamente dañadas por efecto de las labores agrícolas, que han arrancado muros enteros con su cimentación, incluida; como por ejemplo Las Viñas, La Tiesa, la de Camino del Cementerio, La Orden, El Castillo, etc. Pese a ser muchas las que no están excavadas por haber destruidas, el proceso dañino ha permito, poder observar las constantes constructivas que se han podido documentar en las excavaciones sistemáticas llevadas a cabo en las villae excavadas (Gorges y Rodríguez Martín, 2000)
}

seguramente, con la destruida ermita dedicada a San Isidro. En Lácara ocurre otro tanto.

Constructivamente, se evidencia un mismo modo de construir donde prevalecen los opera incerta, con verdugadas de opus testaceum y el tapial. El hormigón de esta fase es bueno aunque no alcanza la dureza ni la calidad que en la fase precedente. Ahora se documenta en el mortero menos proporción de cal, lo que le resta fortaleza, y respecto a los caementa, son de idénticas trazas que anteriormente. En cuanto al signinum decir que ha perdido la fineza y el pulido que antes ofrecía, para pasar a mostrar, en las sucesivas capas, cada vez los trozos de material latericio más grande. A este factor hay que añadir otro: la proporción entre arena y cal no es demasiado adecuada; esto provoca que los suelos se "salten" con mucha facilidad. Intentan subsanar el fallo con la reconstrucción con capas cada vez más potentes, en las que los trozos de ladrillo son cada vez mayores, por lo que el resultado es muy tosco y poco duradero.

De los ss. V y VI, no podemos hacer una sistematización ante la falta de excavaciones de las villas del Guadiana (Rodríguez Martín, 2003). Sabemos, sin embargo, que son muy pocas las villas que continúan, como pueden ser Las Termas, Lácara, Torre Águila, La Cocosa y Pesquero pero no poseemos datos rigurosos, fruto de una excavación y estudio sistemático. 


\section{BIBLIOGRAFÍA}

ADAM, J. P- (1989): La construction romaine, $2^{\mathrm{a}}$ ed. Paris.

CARANDINI, A.; RICCI, A. y VOS, M. de (1982): Filosofiana. La villa di Piazza Armerina. Palermo.

DURÁN CABELLO, R. M. (1991): "La técnica constructiva de la llamada 'Casa-Basílica' de Mérida", La Casa urbana hispanorromana, Zaragoza, pp. 359-364.

(2004): El teatro y el anfiteatro de Augusta Emerita. Contribución al conocimiento histórico de la capital de Lusitania. BAR International Series 1207. Oxford.

GINOUVÈS, R. y MARTÍN, R. (1985): Dictionnaire méthodique de l'architecture grecque et romaine. I. Matériaux, Techniques construction, techniques et formes du décor. Atenas-Roma.

HIDALGO PRIETO, R. (1996): Espacio público y espacio privado en el conjunto palatino de Cercadilla (Córdoba) El aula central y las termas. Córdoba.

LAUBENHEIMER, F. y Le Ny, F. (1999): "Les matériaux de construction en Narbonnaise", $E l$ ladrillo y sus derivados en la época romana, Monografías de Arquitectura Romana 4, Madrid, pp. 11-23.

ROBADOR GONZÁLEZ, M. D. (2000): “Técnica constructiva de las columnas de la domus del Mithraeum en Augusta Emerita, elaboradas con mortero de cal", Memoria 4, Mérida, Excavaciones Arqueológicas 1998, pp. 463488.

RODRÍGUEZ MARTÍN, F. G. (1988): "Prensas y lagares de la villa romana de Torre Águila. Barbaño-Montijo (Badajoz)". Jornadas de viticultura y etnología de tierra de Barros. Almendralejo. X, pp. 223-242.

RODRÍGUEZ MARTÍN, F. G. (1993): Arqueología dela villa de Torre Águila, Cáceres. (Tesis doctoral inédita).

RODRÍGUEZ MARTÍN, F. G. (1999): “Los asentamientos rurales romanos y su posible distribución en la cuenca media del Guadiana", en Rodríguez Martín y Gorges (ed.) Économiae et territoire en Lusitanie romaine, Casa deVelázquez, 65, pp. 121-134.
RODRÍGUEZ MARTÍN, F. G. (2003): "La cuenca media del Guadiana entre los ss. V-VII d.C.. Un espacio en transformación en un contexto de transición", $V$ Encuentros de Historia en Montijo, pp. 19-35.

RODRÍGUEZ MARTÍN, F. G. y GORGES, J. G. (1999): "Prensas de aceite y de vino en una villa romana de la cuenca media del Guadiana (Torre Águila, Barbaño, Badajoz), en Rodríguez Martín y Gorges (ed.) Économiae et territoire en Lusitanie romaine, Casa deVelázquez, 65, pp. 406-426.

ROLDÁN GÓMEZ, L. (1988): "La técnica edilicia en Itálica. Edificios privados", AEspA, 61, pp. 119-140.

(1991): "La casa de la Exedra de Itálica (Santiponce, Sevilla). Un intento de valoración espacial a través de las técnicas constructivas", La Casa urbana hispanorromana, Zaragoza, pp. 303-311.

SALZA PRINA ROCOTI, E. (2001): Villa Adriana il sogno di un imperatore. Roma. 

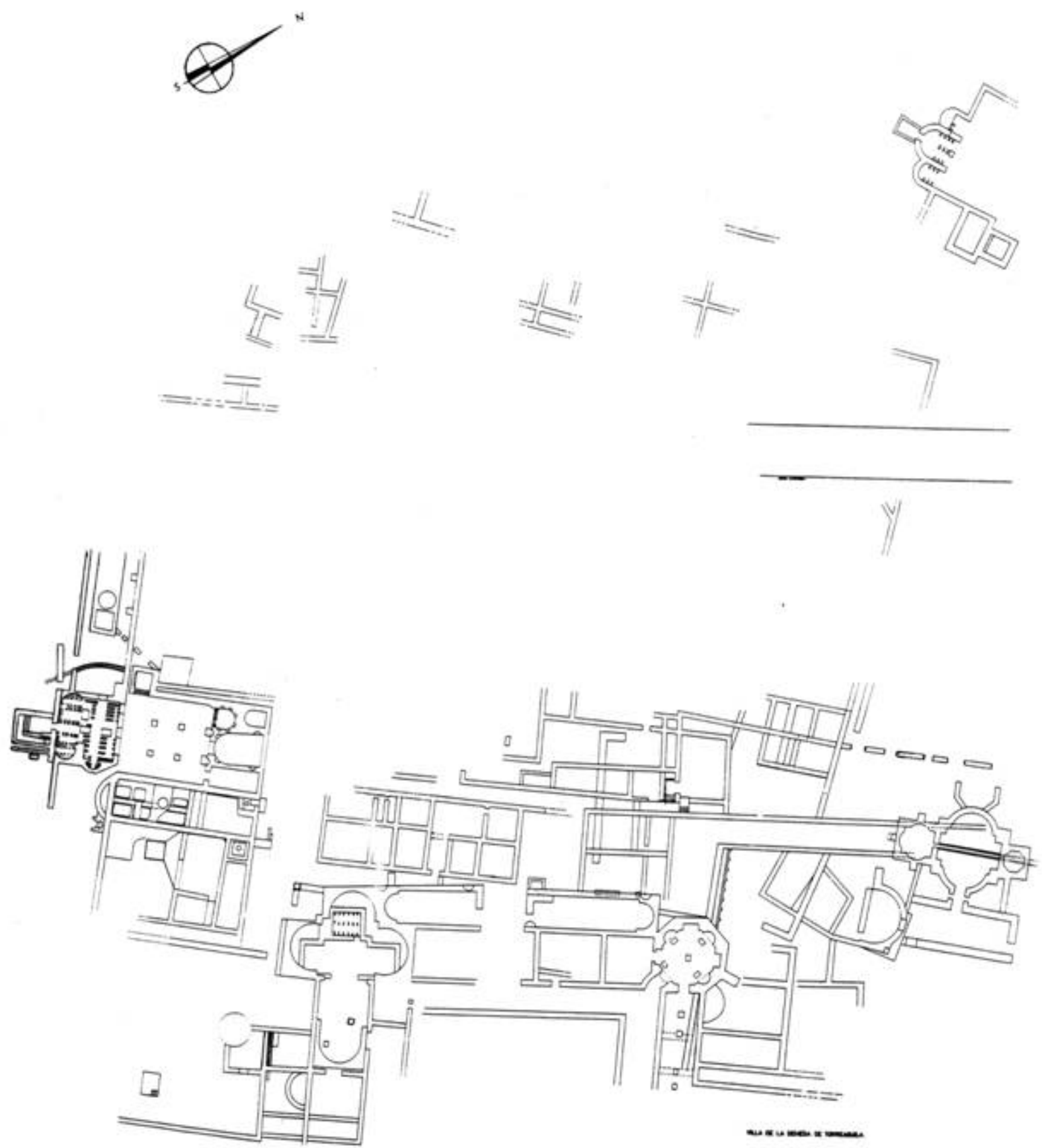

\section{PLANO GENERAL DE LA VILLA ROMANA DE TORRE AGUILA}

Fig. 1.- Plano general de la villa de Torre Águila (Barbaño, Badajoz). 


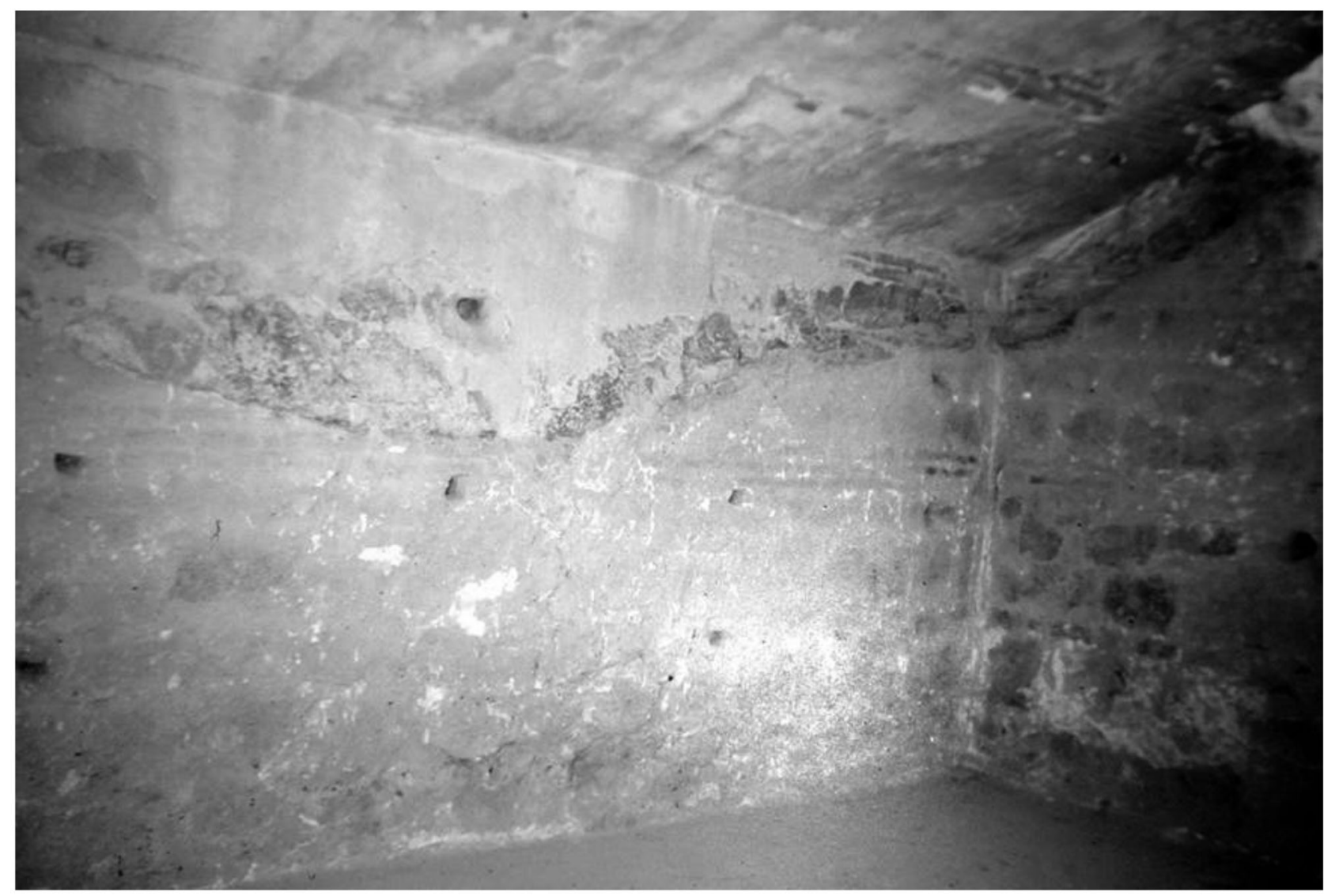

Fig. 2 - Interior del aestivus locus. Detalle del muro y bóveda.

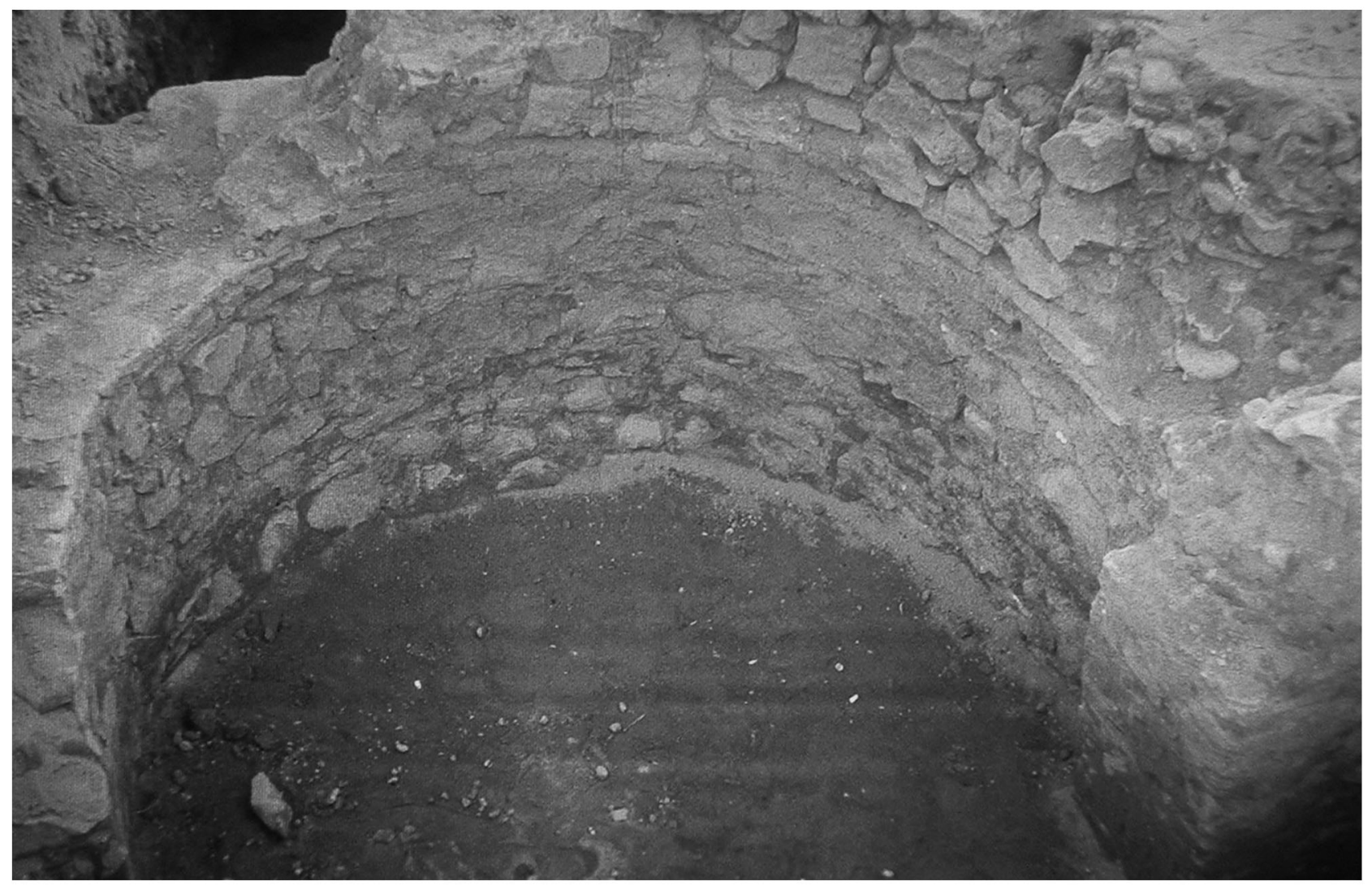

Fig. 3.1 - Opus incertum en el ábside de la villa del siglo IV d.C. Zona de las termas. 


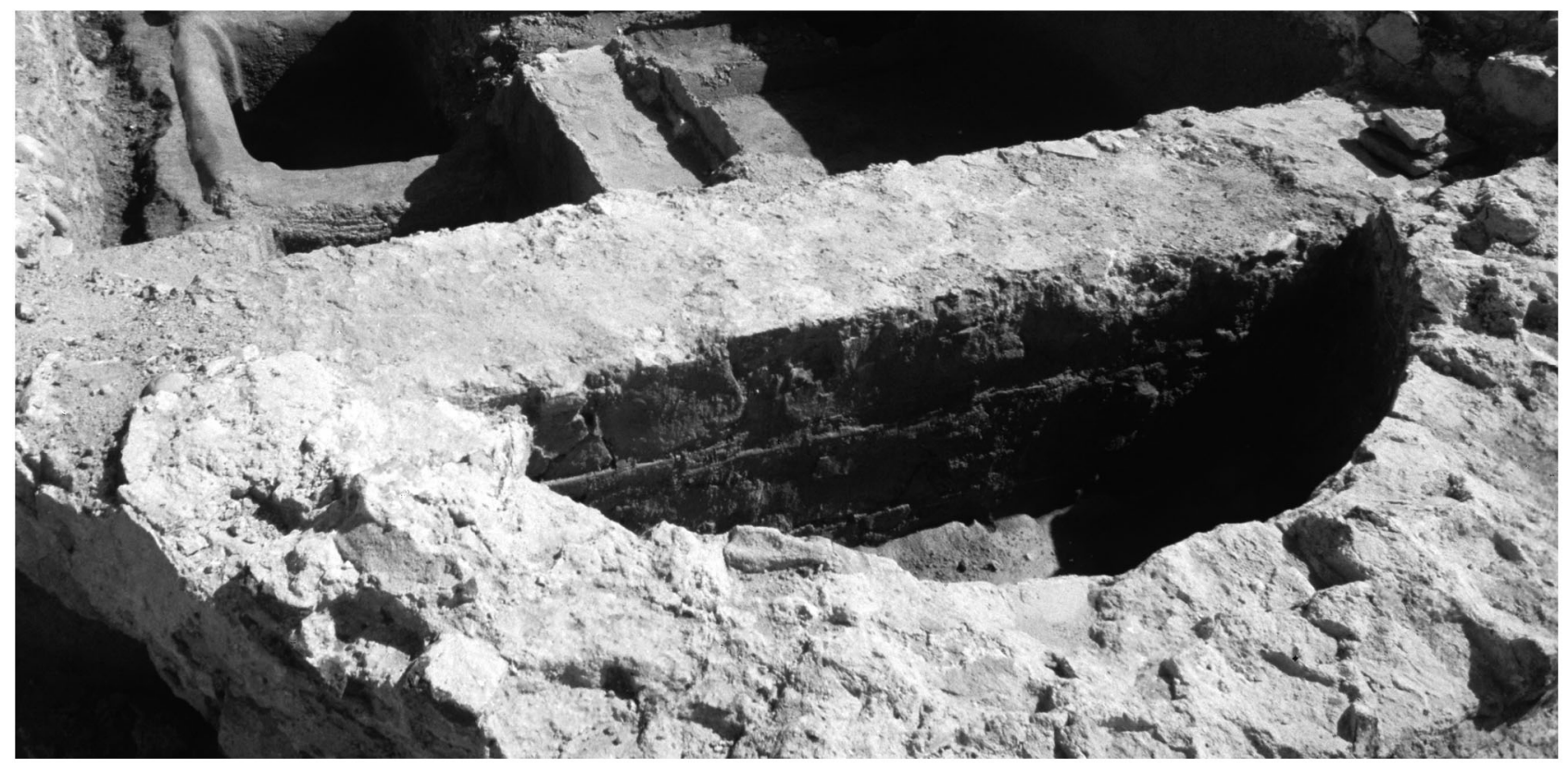

Fig. 3.2 - Muro de cierre del ábside de la almazara. Detalle de la construcción en Opus incertum.

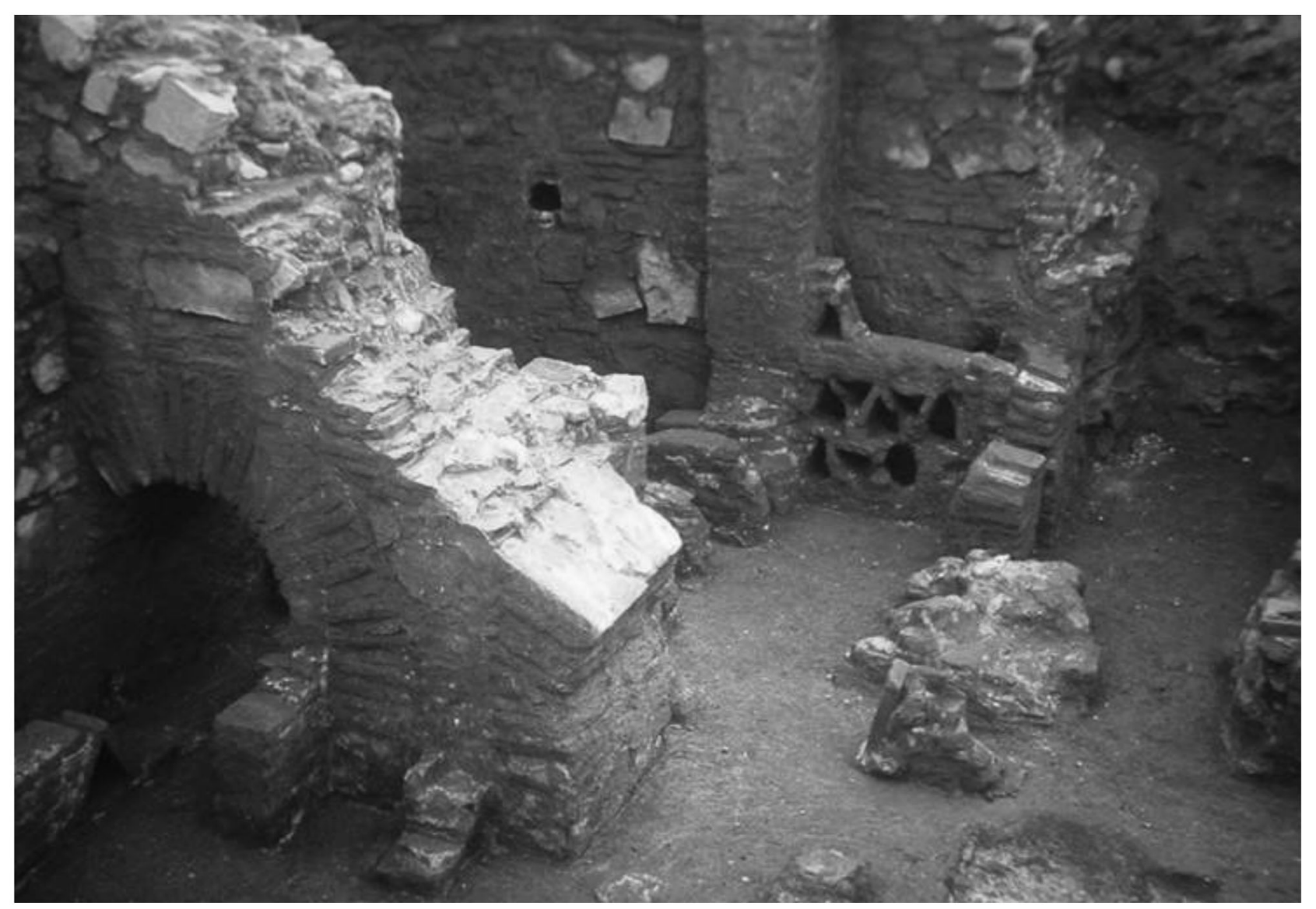

Fig. 4 - Termas de la vivienda del siglo IV. Detalle de la construcción tipo panelado realizado en el hipocaustum. 


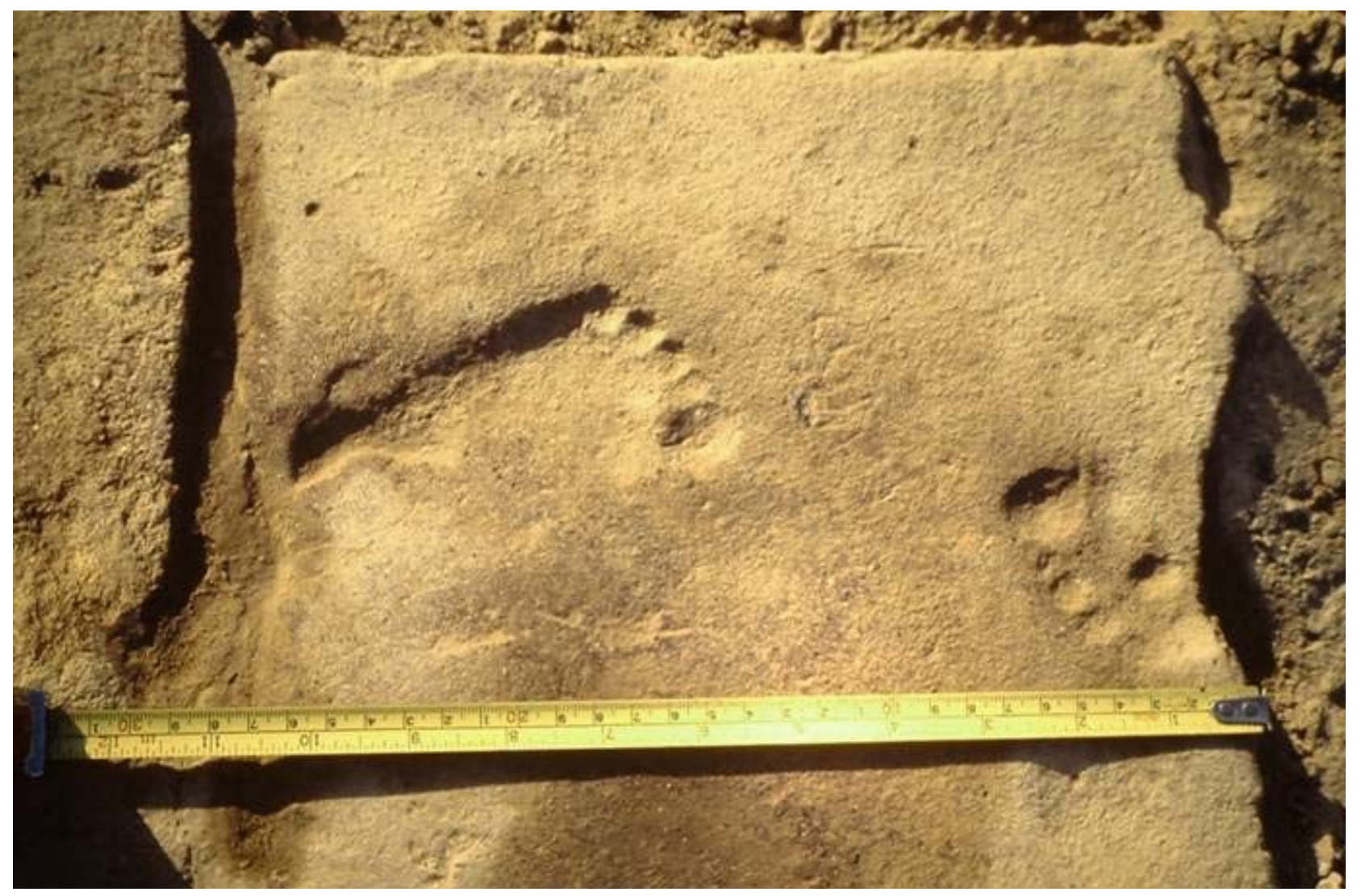

Fig. 5 - Ladrillo con la impronta del pie de un niño de corta edad.

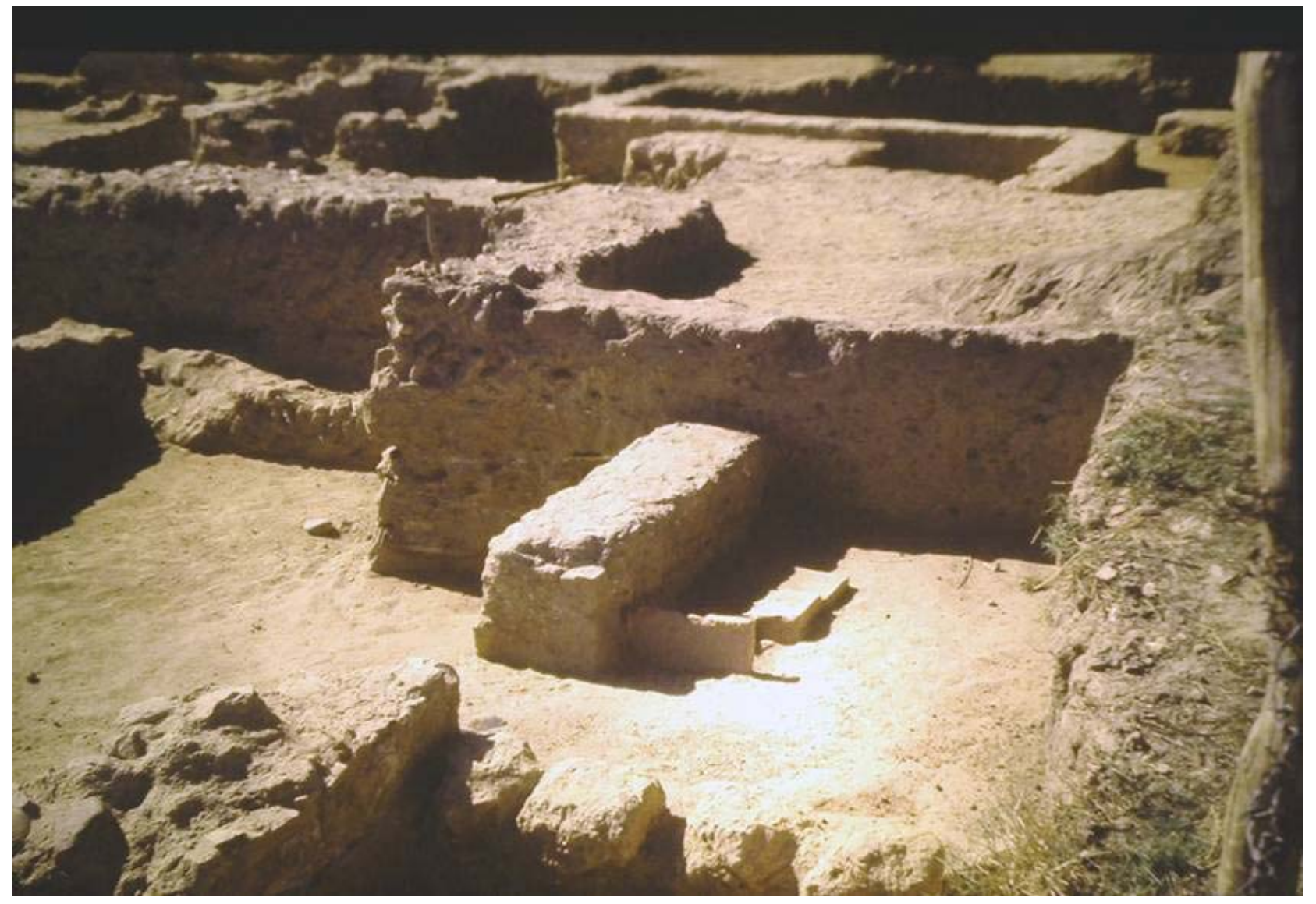

Fig. 6 - Muro de tapial, con decoración pictórica, de la construcción del siglo II d.C. 


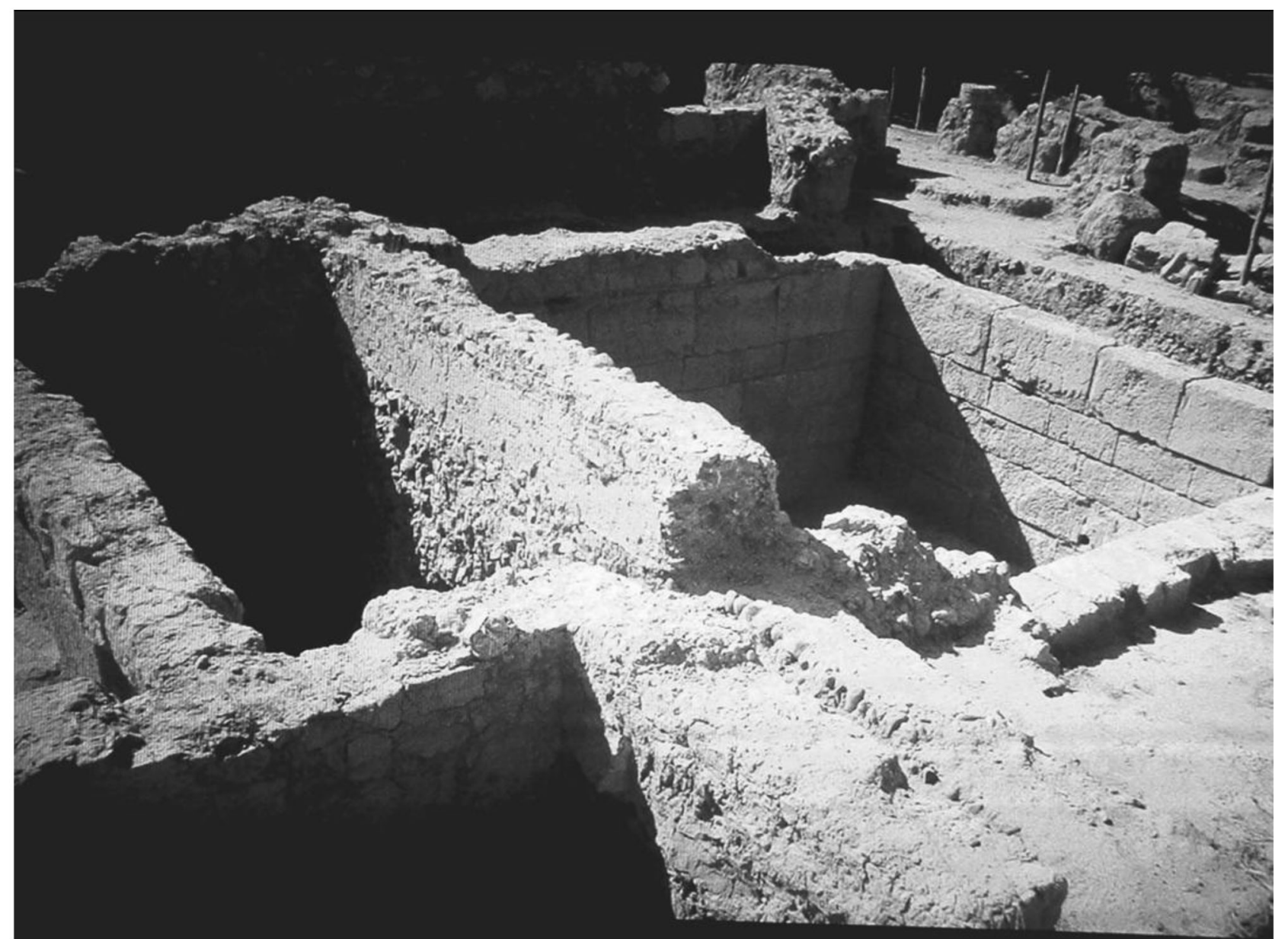

Fig. 7 - Bodega en opus quadratum de la primera edificación de la villa (s. I d.C.). Sobre ella muros de la reforma realizada en esta parte de la hacienda durante el siglo II d.C.

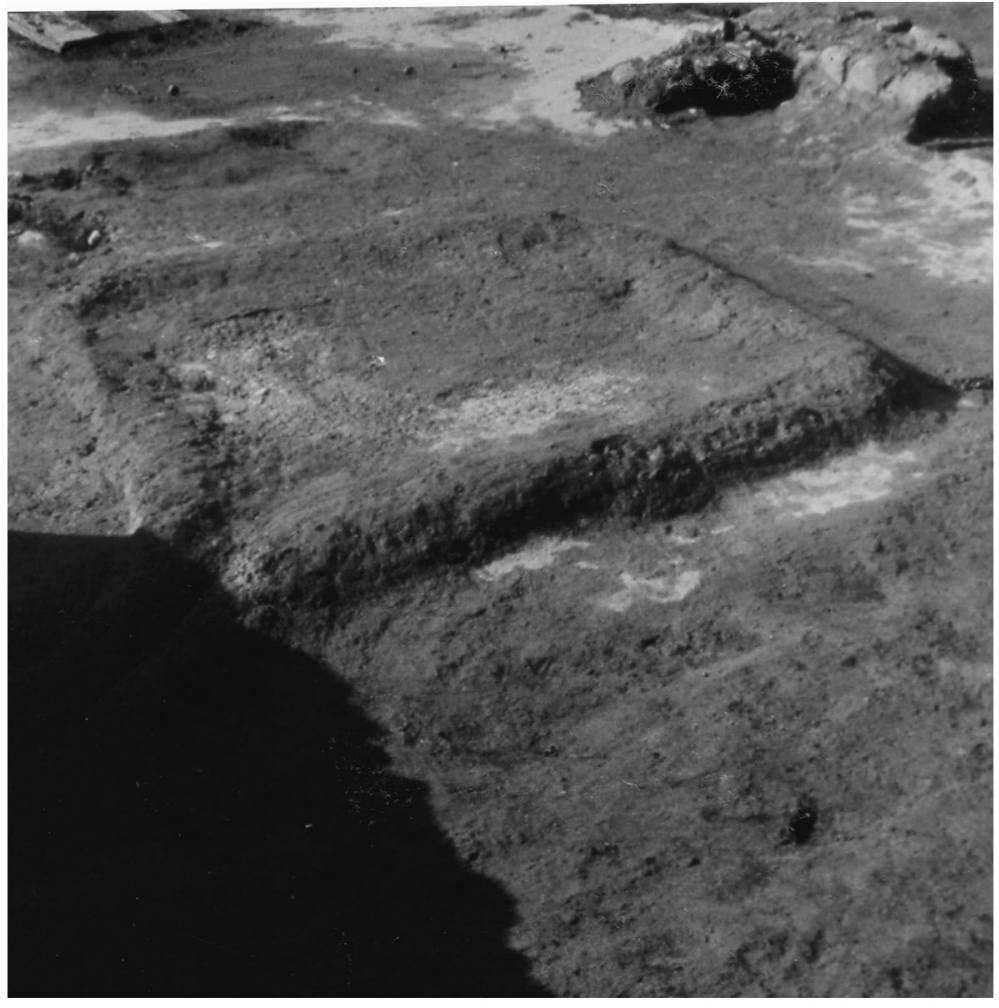

Fig. 8 - Ara perteneciente a las instalaciones del lagar de la villa del siglo IV d.C. Pavimento de opus signinum. 


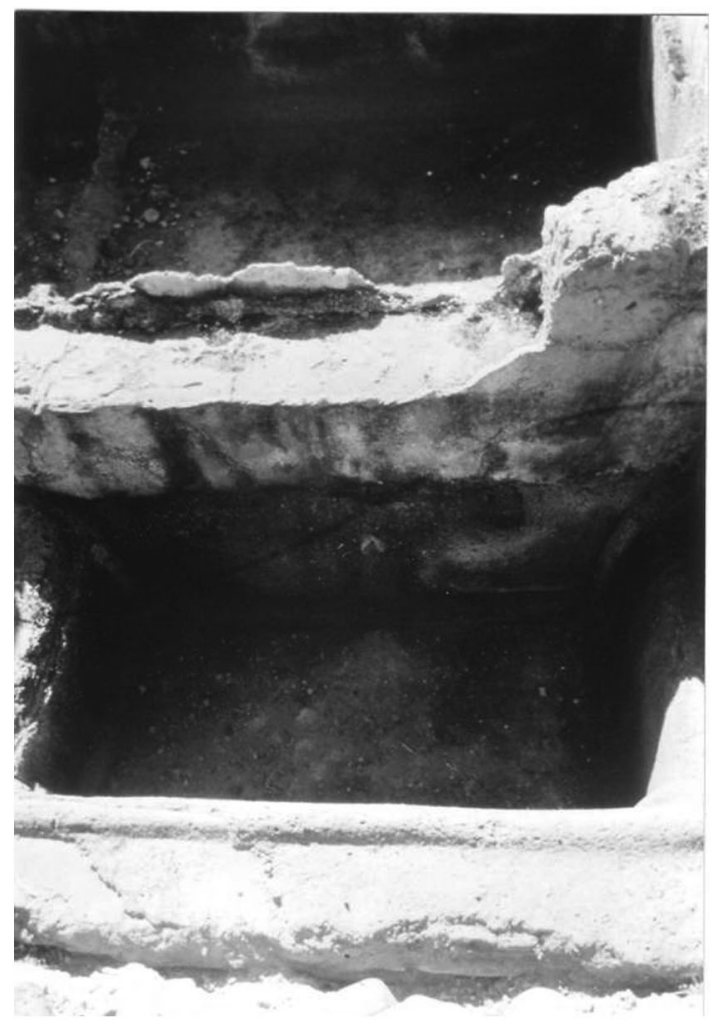

Fig. 9 - Detalle de las labra de la almazara perteneciente a la hacienda del siglo I - II d.C.

detalle del recubrimiento hidráulico.

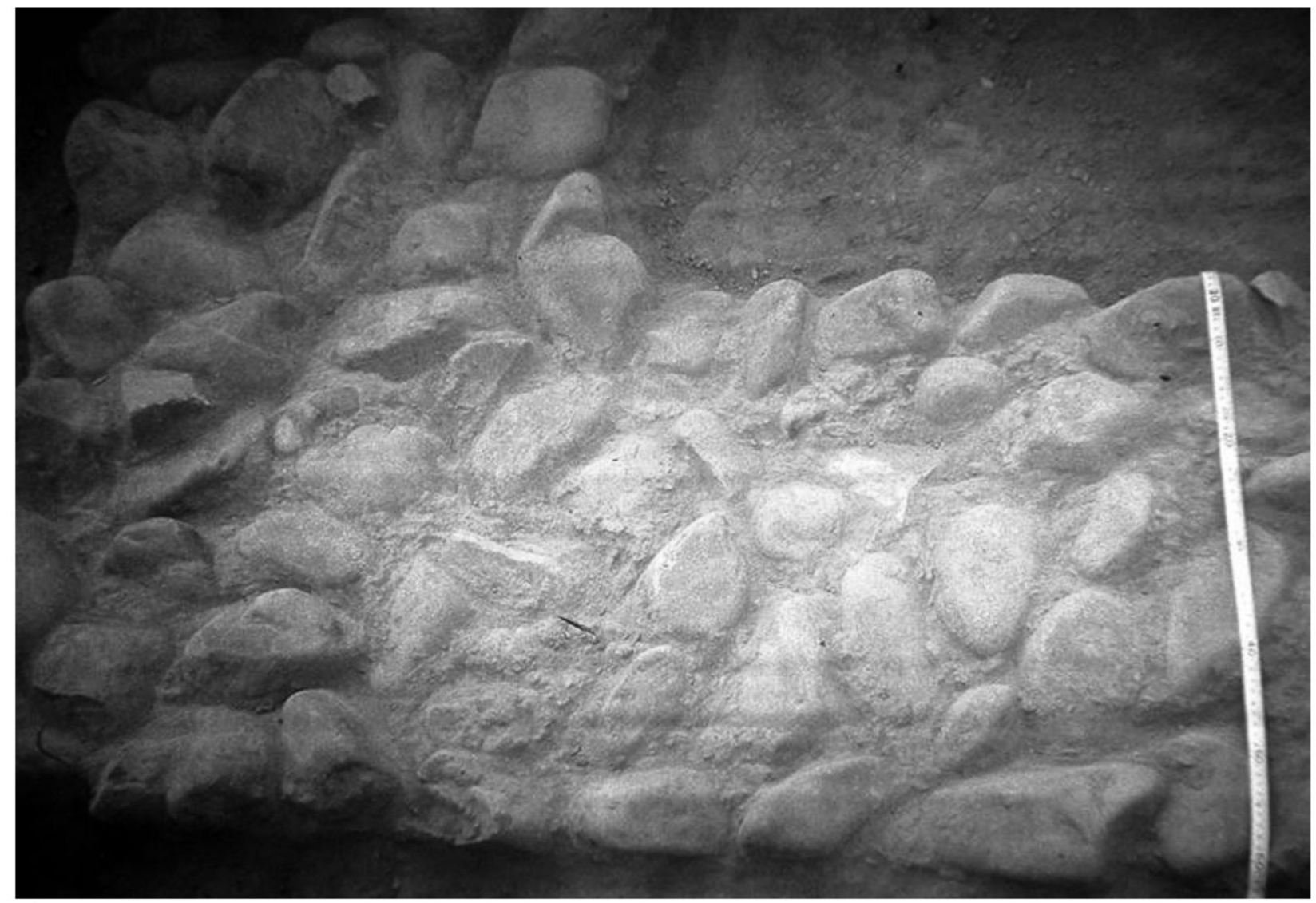

Fig. 10 - Cimentación a base de cantos de río. Villa del siglo I d.C. 


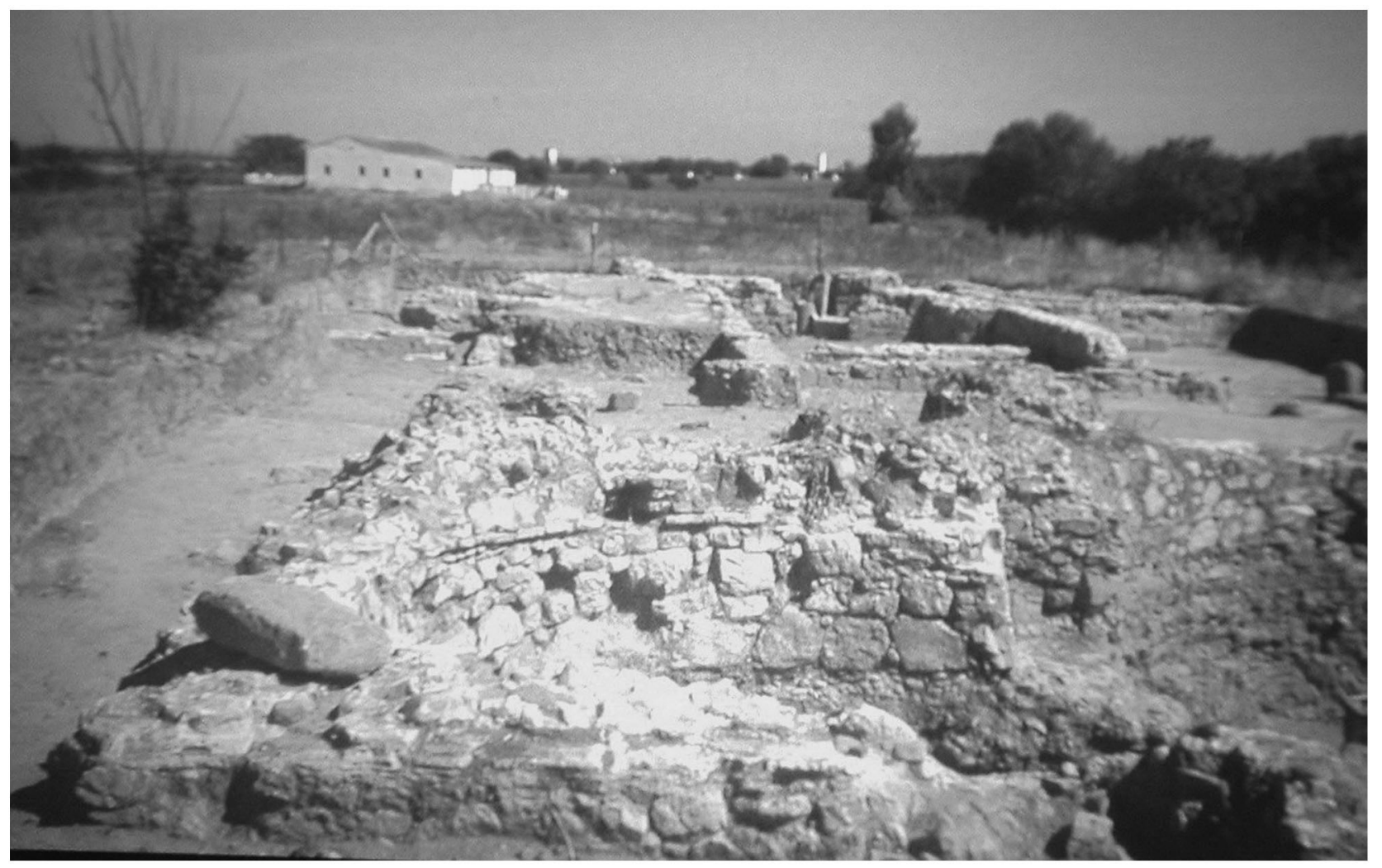

Fig. 11 - Detalle del ábside central de la habitación tetraconca (siglo IV d.C.)

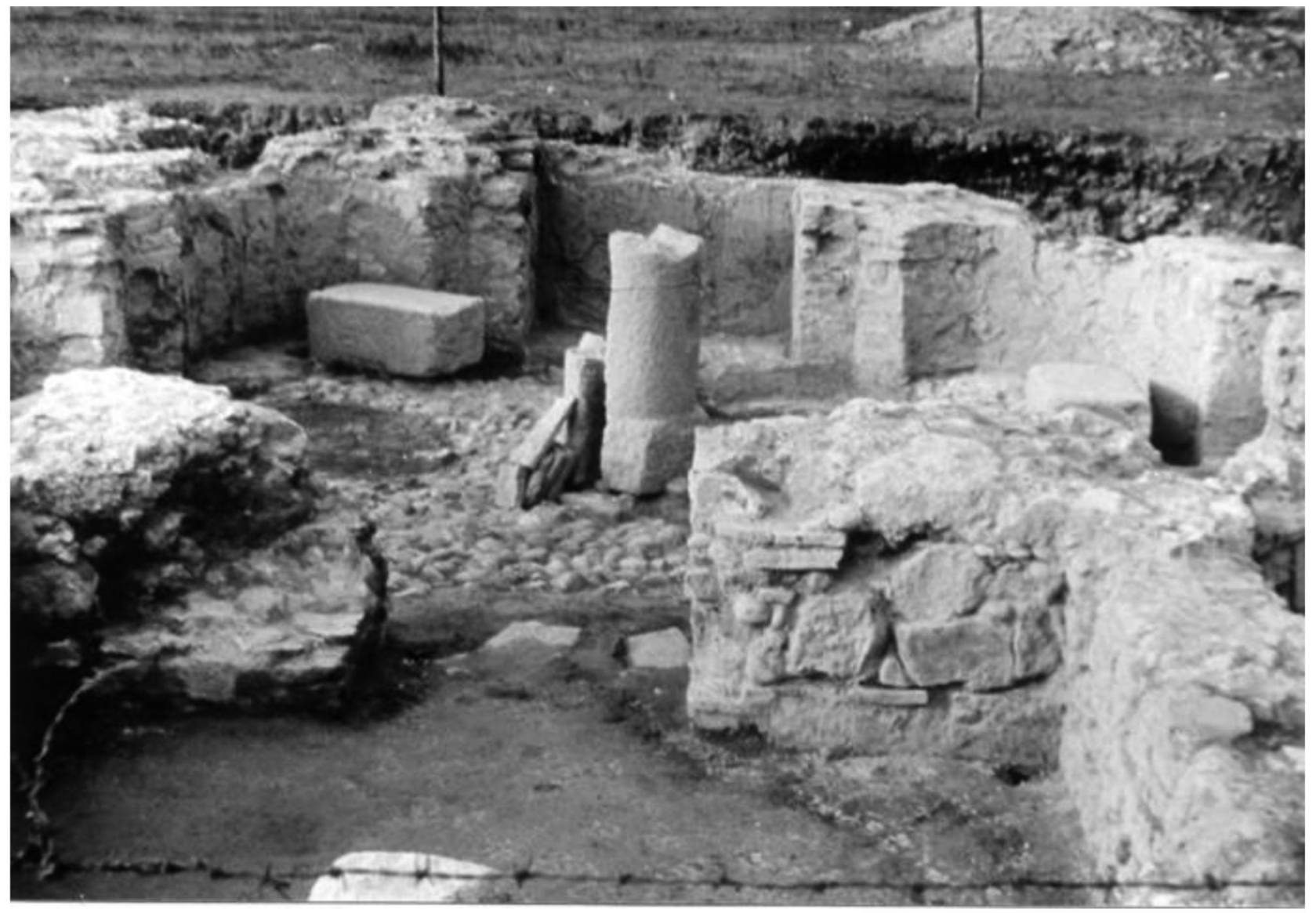

Fig. 12 - Habitación octogonal, estancia perteneciente a la villa del siglo IV d.C.. Detalle de los muros y de la cimentación del pavimento marmóreo a base de cantos de río. 